\title{
Plural Superlatives and Distributivity
}

\author{
Natalia Fitzgibbons, Yael Sharvit and Jon Gajewski \\ University of Connecticut
}

\section{The Distributivity Problem and the Cut-off Problem}

In this paper we propose a unified semantics for singular and plural superlative expressions that makes use of the '**' ("double star") distributivity operator (an operator whose role is to pluralize 2-place predicates). The analysis aims to solve two problems: (a) the distributivity problem (the fact that a superlative expression doesn't distribute over the atomic parts of the plural individual it is predicated of); and (b) the cut-off problem (the fact that a plural superlative expression cannot simultaneously be predicated of two distinct yet overlapping plural individuals). We argue that any solution to these problems that posits two distinct superlative morphemes, one corresponding to a superlative operator for singular individuals and one corresponding to a superlative operator for plural individuals, is challenged by the lack of cross-linguistic morphological evidence. We provide a unified analysis, and account for the differences between plural and singular superlative expressions by appealing to pragmatic principles.

\subsection{The Main Empirical Observations}

The distributivity problem and the cut-off problem of plural superlatives are identified in Stateva (2005), where the empirical observations in (2) are made regarding the sentence in (1), which contains a plural superlative expression (tallest students).

(1) John and Bill are the tallest students.

a. Observation 1: the truth of (1) entails that the property in (i) holds of both John and Bill, but crucially not that the property in (ii) holds of each of them, and not even of one of them.

(i) $[\lambda x: x$ is a singular individual . the tallness of $x$ exceeds the tallness of every student except John and Bill]

(ii) $[\lambda x: x$ is a singular individual . the tallness of $x$ exceeds the tallness of every student except $\mathrm{x}]$

For very helpful comments we thank the audiences of the Linguistics Colloquium at BarIlan University (Ramat-Gan, Israel, 2007), SALT18 (UMass Amherst, 2008), The Conference on Language and Use (Paris, 2008), and the participants of the seminar on the morphology and semantics of degree constructions held at UCONN in Spring 2008. Special thanks go to Toshiko Oda for discussion of the Japanese data. All remaining errors are ours. 
b. Observation 2: If (1) is true, then ' $X$ are the tallest students' may also be true (where $\mathrm{X}$ corresponds to a proper subset or a proper superset of $\{$ John, Bill $\})$.

If Observation 1 were not true, and (1) also entailed that $[\lambda x$. the tallness of $x$ exceeds the tallness of every student except $\mathrm{x}$ ] holds individually of John and of Bill, we would get a contradiction, namely, that John and Bill are taller than each other ('John's tallness exceeds the tallness of every student except John and Bill's tallness exceeds the tallness of every student except Bill').

Observation 2 implies that in a context where (1) holds and Bill is taller than Mary who is taller than Sue (and all the other students are shorter than these four), both (3) and (4) are true.

(3) John, Bill and Mary are the tallest students.

(4) John, Bill, Mary and Sue are the tallest students.

While we agree that Observation 1 holds, we think Observation 2 does not. The reason for this has to do with discourses such as (5) and (6).

A: Who are the best students, John and Bill? Or John, Bill and Fred?

B: I would say John and Bill. It's true that no student is better than Fred but worse than Bill and John, but c'mon! Fred has a D average!

(6) A: John and Bill are the tallest students.

B: You are forgetting Fred; he is only half an inch shorter than Bill.

A: My mistake. John, Bill and Fred are the tallest students.

In (5), A doesn't know which of the two propositions ('John and Bill are the best students', 'John, Bill and Fred are the best students') is true, although he believes one of them is. B's reaction suggests that he believes in the truth of the former but not the latter. In (6), B corrects A, and A accepts the correction (and admits that he was wrong in believing that 'John and Bill are the tallest students' is true, and accepts the truth of 'John, Bill and Fred are the tallest students'). Both cases are at odds with Observation 2.

The well-formedness of these discourses suggests that the context supplies a natural cut-off point on the relevant scale which determines, for a given gradable predicate $\mathrm{R}$, a unique group of R-est individuals (see Herdan 2008). Determining the value of the cut-off point is a complicated matter (see Scontras 2008) and depends on various kinds of contextual information (some of which are supplied by the comparison class itself). The cut-off point is sometimes known, but sometimes the speaker or hearer assumes that there is a unique cut-off point without knowing its value (in which case it can be said to be bound by a context-level existential operator). Like other contextual parameters, the cut-off point may be reset as speakers become more informed. We therefore offer Observation 2' instead. 
Observation 2': If (1) is true in context $\mathrm{C}$, then a. may be true and b. may be true in context $\mathrm{C}$, but no other sentence which follows the schema in $\mathrm{c}$. is true in context $\mathrm{C}$.

a. John is the tallest student.

b. Bill is the tallest student.

c. $[\mathrm{X}$ is/are the tallest student(s)]

Observations 1 and 2' characterize the individual reading of (1). The sentence may also have a group reading. On that reading, a degree of tallness is determined for every relevant group (including the group that consists of John and Bill) which doesn't necessarily equal the degree of tallness of any one particular individual in the group (for concrete proposals regarding how this degree is determined, see Matushansky and Ruys 2006, and Scontras 2008). Although we are not concerned here with the group reading of plural superlatives, it is worth noting that Observation 1 holds of that reading too. For example, The Italian students and the French students are the best students, where the subject term refers to two groups, doesn't entail that the property $[\lambda \mathrm{x}: \mathrm{x}$ is a group of singular individuals. the goodness of $\mathrm{x}$ exceeds the goodness of every other group of students except $x$ ] holds of the Italian students group and the French students group; only the property $[\lambda x: x$ is a group of singular individuals. the goodness of $x$ exceeds the goodness of every other group of students except for the Italian group and the French group] does. And here, too, the context supplies a cut-off point which both the Italian students, as a group, and the French students, as a group, must exceed.

The goal of this paper is to provide an analysis of the individual reading of (1) that is compatible with Observations 1 and 2'.

\subsection{Why Observation 1 is a Problem}

As shown by Stateva (2005), any semantics for -est which presupposes that the external argument of -est is a member of the contextually-supplied comparison set, coupled with the assumption that plural morphology indicates the presence of a VP-level distributive '*'-operator (see Link 1983, Landman 1989, Schwarzschild 1996 and others), works well for singular superlatives, but yields for (1) the contradictory reading from Observation 1. We illustrate this point using Heim's (1999) semantics, but the same point can be made for other proposals.

The assumptions in (8)-(9), regarding the interpretation of gradable adjectives and the superlative morpheme, yield for John is the tallest student, with a singular superlative, the interpretation in (10).

(8) a. For any $d$ of type $d$ (degree) and any singular $x$ of type $e$ (individual), $[$ tall $](\mathrm{d})(\mathrm{x})=$ True iff $\mathrm{x}$ 's tallness is at least $\mathrm{d}$.

b. Type shifting operation: $\left[\lambda R \in D_{<d,<e, t>>} . \lambda P \in D_{<e, t>} . \lambda d \in D_{d} . \lambda x \in D_{e}\right.$. $\mathrm{R}(\mathrm{d})(\mathrm{x})$ and $\mathrm{P}(\mathrm{x})]$. 
c. [tall student $](\mathrm{d})(\mathrm{x})=$ True iff $\mathrm{x}$ is a (singular) student and $\mathrm{x}$ 's tallness is at least $\mathrm{d}$ (by combining tall and student via the type shifting operation in (8b)).

(9) For any $\mathrm{R}$ of type $\langle\mathrm{d},<\mathrm{e}, \mathrm{t}>>\text { and any } \mathrm{x} \text { (type e), [-est }]^{\mathrm{C}}(\mathrm{R})(\mathrm{x})$ is defined only if: (i) $\mathrm{x} \in \mathrm{C}$, and (ii) for all $\mathrm{y} \in \mathrm{C}$ : there is a degree $\mathrm{d}$ such that $R(d)(y)=$ True.

Whenever defined, $\llbracket-e s t \rrbracket^{C}(\mathrm{R})(\mathrm{x})=$ True iff there is a d such that $\mathrm{R}(\mathrm{d})(\mathrm{x})$ $=$ True and for all $\mathrm{y} \neq \mathrm{x}$ such that $\mathrm{y} \in \mathrm{C}: \mathrm{R}(\mathrm{d})(\mathrm{y})=$ False.

(10) Whenever defined (in particular, when all members of $\mathrm{C}$ are students who are tall to some degree and John $\in \mathrm{C})$, [I John [(be) [-est [tall student]]] $]^{C}=$ True iff John is taller than any $\mathrm{y} \in \mathrm{C}$ such that $\mathrm{y} \neq \mathrm{J}$ ohn.

As for pluralization, let us adopt a simplified version of the view advocated in Schwarzschild 1996, according to which pluralities are non-singleton sets of singular individuals (and for any singular individual $\mathrm{x}, \mathrm{X}=\{\mathrm{x}\}$; see Quine 1969). The assumptions in $(11 \mathrm{~b}, \mathrm{c})$ regarding the pluralization of 1-place predicates such as left by the distributivity operator '*' (which yield (11a) as the interpretation of John and Bill left), coupled with the assumptions regarding the interpretation of tall and -est in (8) and (9), yield the contradictory (12) as the interpretation of (1).

(11) a. $\llbracket[$ John and Bill $] *$ left $\rrbracket=$ True iff John left and Bill left.

b. For any set $\mathrm{P}, * \mathrm{P}$ is the smallest set such that:

(i) $\mathrm{P} \subseteq * \mathrm{P}$, and

(ii) If $\mathrm{a} \in * \mathrm{P}$ and $\mathrm{b} \in * \mathrm{P}$, then $\mathrm{a} \cup b \in * \mathrm{P}$.

c. If the characteristic set of [left] is $\{\mathrm{John}$, Bill, Mary\}, then the characteristic set of $\llbracket * l e f t]$ is $\{\mathrm{John}$, Bill, Mary, \{John, Bill\}, $\{$ John, Mary\}, \{Bill, Mary\}, \{John, Bill, Mary\}\}.

(12) Whenever defined (in particular, when all members of $\mathrm{C}$ are students with some degree of tallness and Bill $\in \mathrm{C}$ and John $\in \mathrm{C}$ ), [John and Bill $*[($ be $)$ [-est [tall student $]]] \mathbb{I}^{C}=$ True iff John is taller than any $\mathrm{y} \in \mathrm{C}$ such that $\mathrm{y} \neq \mathrm{John}$, and Bill is taller than any $\mathrm{y} \in \mathrm{C}$ such that $\mathrm{y} \neq \mathrm{Bill}$.

The problem with the LF in (12), as noticed by Stateva, is that -est is in the scope of '*', which leads to the attribution of 'being tallest student' to both members of the subject term.

We may want to ask whether (13), where ' $*$ ' is not attached directly to the noun and is outside the scope of -est, is a viable alternative.

\section{[John and Bill [(be) [-est [tall *student $]]]$}

Suppose we remove from (8a) the requirement that tall apply to singularities. If we then combine tall with *student via the type shifting operation in (8b), we get: $\left[\lambda d \in D_{d} \cdot \lambda x \in D_{e} \cdot x\right.$ is a singularity or a plurality of students and $x$ is at least d-tall]. But what does it mean for a plurality to be tall to some degree? Within the framework outlined so far, predicates such as [tall *student] are not 
defined. Suppose, for the sake of discussion, that we stipulate that [tall $*_{\text {student }}$ is true of a plural individual $\mathrm{x}$ and a degree $\mathrm{d}$ if and only if all singular members of $\mathrm{x}$ are at least d-tall. Since our semantics for -est in (9) doesn't require its external argument to be a singularity, we get the following non-contradictory (and intuitively correct) truth conditions for (1).

(14) Whenever defined (in particular, when Bill $\in \mathrm{C}$ and John $\in \mathrm{C}$ ), [IJohn and Bill [-est [tall *student] $] \mathbb{I}^{\mathrm{C}}=$ True iff the plurality $\{\mathrm{John}$, Bill $\}$ is taller than any other member of $\mathrm{C}$.

The distributivity problem is thus solved.

We come back to the LF in (13) in section 3 (where we look at several alternatives to our own proposal, outlined in section 2), and examine it in more detail. For the moment, it is sufficient to acknowledge that (12) leads to contradictory truth conditions, and that (13) requires a definition of degrees that renders predicates such as $[$ tall *student $]$ applicable to a plurality.

\subsection{Why Observation 2' is a Problem}

Even if we solve the distributivity problem using (13), obtaining the truth conditions in (14), the cut-off problem remains: if Mary is shorter than Bill and John, but taller than all the others, the prediction is that the truth of (1) entails the truth of John, Bill and Mary are the tallest students, which is at odds with Observation 2'. To solve the cut-off problem, one might be tempted to posit two superlative morphemes. Plural morphology, on this view, is a reflex of the plural superlative morpheme (and not of ' $*$ ').

One concrete implementation of this idea states that the singular superlative $-e s t^{\mathrm{SG}}$ has the semantics in (15) and that the plural superlative -est ${ }^{\mathrm{PL}}$ has the semantics in (16) (where cut-off(C) is the cut-off degree supplied by $\mathrm{C}$, and $\operatorname{comp}(\mathrm{C})$ is the comparison set supplied by C; cf. Herdan (2008)). - est ${ }^{\mathrm{PL}}$ is inherently distributive.

(15) $\quad\left[-e s t^{\mathrm{SG}}\right]^{C}(\mathrm{R})(\mathrm{x})$ is defined only when: (i) $\mathrm{x}$ is a singularity; (ii) $\mathrm{x} \in \mathrm{C}$, (iii) for all $y \in C$ there is a degree $d$ such that $R(d)(y)=$ True.

Whenever defined, $\left[-e s t^{\mathrm{PL}} \mathbb{C}^{\mathrm{C}}(\mathrm{R})(\mathrm{x})=\right.$ True iff there is a degree $\mathrm{d}$ such that $\mathrm{R}(\mathrm{d})(\mathrm{x})=$ True and for every $\mathrm{y}$ in $\mathrm{C}$ distinct from $\mathrm{x}, \mathrm{R}(\mathrm{d})(\mathrm{y})=$ False.

[I-est $\left.{ }^{\mathrm{PL}}\right]^{\mathrm{C}}(\mathrm{R})(\mathrm{X})$ is defined only when: (i) $\mathrm{X}$ is a plurality; (ii) $\mathrm{X} \in \mathrm{C}$, (iii) for all $Y \in C$ : for all $y \in Y$ there is a degree $d$ such that $R(d)(y)=$ True, and Y doesn't overlap $\mathrm{X}$.

Whenever defined, $\llbracket-e s t^{\mathrm{PL}} \prod^{\mathrm{C}}(\mathrm{R})(\mathrm{X})=$ True iff for every $\mathrm{x} \in \mathrm{X}, \mathrm{R}$ (cut$\operatorname{off}(\mathrm{C}))(\mathrm{x})=$ True and for every $\mathrm{Y} \in(\mathrm{C}-\{\mathrm{X}\})$, for every $\mathrm{y} \in \mathrm{Y}, \mathrm{R}$ (cut$\operatorname{off}(\mathrm{C}))(\mathrm{y})=$ False.

This yields (17) as the LF and interpretation for (1).

Whenever defined, [IJohn and Bill [-est ${ }^{\mathrm{PL}}[$ tall student $\left.\left.]\right]\right]^{\mathrm{C}}=$ True iff John's tallness is at least the cut-off point of C and Bill's tallness is at 
least the cut-off point of C (so Bill and John could be equally tall or not), but for all other $\mathrm{x}$, the tallness of $\mathrm{x}$ is less than the cut-off of $\mathrm{C}$.

These are indeed the intuitive truth conditions, and from that perspective, the solution is viable. Notice that by solving the cut-of problem with the help of an inherently distributive $-e s t^{\mathrm{PL}}$, the distributivity problem is also solved. Thus, we note that the two problems are not completely unrelated: it is true that one could imagine a state of affairs where Observation 1 holds but Observation 2' does not (indeed, this is the state of affairs which Stateva describes), but one cannot imagine a state of affairs where the opposite is true.

Interestingly, the two problems are also related by the fact that no analysis that stipulates the existence of two distinct superlative morphemes (e.g., (15) and (16)) is supported by cross-linguistic morphological evidence. In fact, such evidence strongly suggests that there is only one superlative morpheme. No language (that we are aware of) has two distinct lexical items corresponding to singular and plural superlatives. There are languages that make a singular/plural distinction morphologically, but in those languages plural morphology is always on the noun (and may "spread" by agreement, as in the Russian example in (18)); but it is never exclusively on the superlative morpheme.

$$
\begin{aligned}
& \text { Everest i K2 - samye vysokije gory } \\
& \text { Everest and K2 most.pl. high.pl mountains.pl } \\
& \text { 'Everest and K2 are the highest mountains.' }
\end{aligned}
$$

There are also languages that have more than one superlative morpheme. Japanese is a language that has two items corresponding to -est: ichiban and mottomo. The former is used with expressions denoting singular individuals and the latter is used with both (in fact, Toshiko Oda informs us that while ichiban is not completely unacceptable with plural expressions, mottomo is certainly preferred). This brings up the possibility that ichiban corresponds to (15), and mottomo to (9).
a. John-ga ichiban takai yama-ni mobotta John-nom most high mountain-to climbed 'John climbed the highest mountain'
b. ??John-ga ichiban takai yamayama-ni mobotta John-nom most high mountains-to climbed 'John climbed the highest mountains'
c. John-ga mottomo takai yama-ni mobotta John-nom most high mountain-to climbed 'John climbed the highest mountain'
d. John-ga mottomo takai yamayama-ni mobotta John-nom most high mountains-to climbed 'John climbed the highest mountain'

The point is that even Japanese doesn't have a morpheme that is used exclusively with expressions that denote plural individuals, and plural morphology appears on the noun, as in English, which means that the problematic LF in (12) would still be generated. In addition, there is probably 
an independent reason why ichiban usually doesn't sound good with plural superlatives: it literally means "number one" (which makes ichiban takai similar to the English the single highest, which also cannot be used with plural denoting nouns).

For this reason our proposal, which is outlined in the next section, does not posit two such lexical items. We begin by offering a semantics that solves the distributivity problem, and then we make the necessary amendments required to solve the cut-off problem.

\section{The Proposal}

We propose $(21)$ - with '**' on tall and '*' on student - as an alternative to the problematic LF in (12) (repeated below as (20)). In (21) -est is neither in the scope of ' $*$ ' nor of ' $* *$ '.

\section{[John and Bill *[-est [tall student $]]$}

\section{[John and Bill [-est [**tall *student]]]}

When attached to verbs that denote $<\mathrm{e},<\mathrm{e}, \mathrm{t}>>$-functions, '**, delivers functions of the kind shown in $(22 \mathrm{~b}, \mathrm{c}, \mathrm{d})$, which are meant to derive the intuitive truth conditions of sentences such John and Bill love Mary and Sue (as in (22a); see Sternefeld 1998 and Beck 2001).

(22) a. [[ [John and Bill] **love [Mary and Sue ] ]= True iff each member of $\{$ John, Bill $\}$ loves at least one member of $\{$ Mary, Sue $\}$, and each member of $\{$ Mary, Sue $\}$ is loved by at least one member of $\{$ John, Bill\}.

b. For any relation $\mathrm{R}, * * \mathrm{R}$ is the smallest relation such that:

(i) $\mathrm{R} \subseteq * * \mathrm{R}$, and

(ii) If $<\mathrm{a}, \mathrm{b}>\in * * \mathrm{R}$ and $<\mathrm{c}, \mathrm{d}>\in * * \mathrm{R}$, then $<\mathrm{a} \cup \mathrm{c}, \mathrm{b} \cup \mathrm{d}>\in * * \mathrm{R}$

c. If the characteristic set of [love] is $\{<\mathrm{John}$, Mary $>,<$ Bill, Sue $>$ \}, then the characteristic set of $\left[{ }^{* *}\right.$ love $]$ is $\{<\mathrm{John}$, Mary $>,<$ Bill, Sue $>,<\{$ John, Bill $\},\{$ Mary, Sue $\}>$.

d. $\llbracket * *$ love $\rrbracket(\mathrm{Y})(\mathrm{X})$ is defined only if:

Whenever there is a $\mathrm{x} \in \mathrm{X}$ and a $\mathrm{y} \in \mathrm{Y}$ such that $\llbracket$ love $\rrbracket(\mathrm{y})(\mathrm{x})=$ True, then for all $\mathrm{x} \in \mathrm{X}$ there is a $\mathrm{y} \in \mathrm{Y}$ such that $\llbracket$ love $\rrbracket(\mathrm{y})(\mathrm{x})=$ True, and for all $\mathrm{y} \in \mathrm{Y}$ there is a $\mathrm{x} \in \mathrm{X}$ such that $\llbracket$ love $\rrbracket(\mathrm{y})(\mathrm{x})=$ True.

Whenever defined, $\left[{ }^{* *}\right.$ love $](\mathrm{Y})(\mathrm{X})=$ True iff there is a $\mathrm{x} \in \mathrm{X}$ and a $\mathrm{y} \in \mathrm{Y}$ such that $\llbracket$ love $\rrbracket(\mathrm{y})(\mathrm{x})=$ True.

Note that the definedness condition (i.e., presupposition) in (22d) is stated in the form of a conditional 'if $p$, then q'. This means that for (22a) to be false, John must love neither Mary nor Sue and Bill must love neither Mary nor Sue.

Positing this presupposition is supported by the judgment that (23) appears to convey that neither John nor Bill loves either Mary or Sue (cf. Beck 2001; see also Löbner 1987 and Schwarzschild 1994).

John and Bill don't love Mary and Sue. 
If instead of (22) (with its presupposition), we had the semantics for **love in (24) (without this presupposition), we would not account for the intuitions regarding (23).

(24) $\llbracket * *$ love $\rrbracket(Y)(X)=$ True iff for all $\mathrm{x} \in \mathrm{X}$ there is a $\mathrm{y} \in \mathrm{Y}$ such that $\llbracket$ love $](\mathrm{y})(\mathrm{x})=$ True, and for all $\mathrm{y} \in \mathrm{Y}$ there is a $\mathrm{x} \in \mathrm{X}$ such that [love $\rrbracket(\mathrm{y})(\mathrm{x})=$ True.

In other words, in a situation where Sue is loved by John and Bill but Mary is not loved by either of them, (23) would come out true, contrary to fact.

We assume that ' $* *$ ' may attach to expressions that denote $<\mathrm{d},<\mathrm{e}, \mathrm{t}>>$ functions, in which case it delivers functions of the kind shown in (25).

a. If the characteristic set of $\llbracket$ tall $\rrbracket$ is $\{\langle\mathrm{d} 1, \mathrm{John}\rangle,\langle\mathrm{d} 2$, Bill $>\}$, then the characteristic set of $\llbracket * *$ tall $\rrbracket$ is $\{<\mathrm{d} 1, \mathrm{John}>,<\mathrm{d} 2, \mathrm{Bill}>,<\{\mathrm{d} 1$, $\mathrm{d} 2\},\{$ John, Bill $\}>\}$.

b. $\left[{ }^{* *} \operatorname{tall} \rrbracket(\mathrm{D})(\mathrm{X})\right.$ is defined only if:

Whenever there is a $\mathrm{d} \in \mathrm{D}$ and $\mathrm{a} \in \mathrm{x} \in \mathrm{X}$ such that $\llbracket$ tall $](\mathrm{d})(\mathrm{x})=$ True, then for all $\mathrm{d} \in \mathrm{D}$ there is a $\mathrm{x} \in \mathrm{X}$ such that $\llbracket$ tall $](\mathrm{d})(\mathrm{x})=$ True and for all $\mathrm{x} \in \mathrm{X}$ there is a $\mathrm{d} \in \mathrm{D}$ such that $[$ tall $](\mathrm{d})(\mathrm{x})=$ True.

Whenever defined, $\left[{ }^{*} *\right.$ tall $](\mathrm{D})(\mathrm{X})=$ True iff there is a $\mathrm{d} \in \mathrm{D}$ and a $\mathrm{x} \in \mathrm{X}$ such that $\llbracket$ tall $](\mathrm{d})(\mathrm{x})=$ True.

c. Whenever defined, $[* *$ tall $*$ student $](\mathrm{D})(\mathrm{X})=$ True iff there is a $\mathrm{d} \in \mathrm{D}$ and a $\mathrm{x} \in \mathrm{X}$ such that $\llbracket$ tall $\rrbracket(\mathrm{d})(\mathrm{x})=$ True and [student $\rrbracket(\mathrm{x})=$ True.

In addition, we assume that - est has the semantics in (26), yielding for (1) an interpretation compatible with Observation 1.

(26) $[- \text {-est }]^{\mathrm{C}}(\mathrm{R})(\mathrm{X})$ is defined only if: (i) $\mathrm{X} \in \mathrm{C}$, (ii) for all $\mathrm{Y} \in \mathrm{C}$ such that $\mathrm{Y} \neq \mathrm{X}$ : $\mathrm{Y}$ doesn't overlap $\mathrm{X}$, and (iii) for all $\mathrm{Y} \in \mathrm{C}$ : there is a (singularity or plurality of degrees) $\mathrm{D}$ such that $\mathrm{R}(\mathrm{D})(\mathrm{Y})=$ True.

Whenever defined, $[-e s t]^{C}(\mathrm{R})(\mathrm{X})=$ True iff there is a $\mathrm{D}$ such that $R(D)(X)=$ True and for all $Y \neq X$ such that $Y \in C: R(D)(Y)=$ False.

Since $X$ in (26) is not required to be a plurality - it can be either a singularity or a plurality - the semantics is good for both John is the tallest student and John and Bill are the tallest students.

(27) Whenever defined, $[$ John [-est [tall student $]] \mathbb{C}^{\mathrm{C}}=$ True iff there is a singular degree $\mathrm{d}$ such that $\llbracket$ tall student $\rrbracket(\mathrm{d})(\mathrm{x})=$ True and for all $\mathrm{y} \neq$ John, [tall student $](\mathrm{d})(\mathrm{y})=$ False.

(28) Whenever defined, $\llbracket$ John and Bill [-est [**tall $*$ student $]]]^{C}=$ True iff there is a plurality of degrees $\mathrm{D}$ such that [1**tall $\left.*_{\text {student }}\right](\mathrm{D})(\{\mathrm{John}, \mathrm{Bill}\})=$ True and for all $\mathrm{Y} \neq\{\mathrm{John}, \mathrm{Bill}\}$ such that $\mathrm{Y} \in \mathrm{C},\left[{ }^{* *}\right.$ tall $*$ student $](\mathrm{D})(\mathrm{Y})=$ False. 
If instead of (25) (with its presupposition) we had the semantics in (29) for **tall (cf. (24)), we would incorrectly predict (1) (John and Bill are the tallest students, or its LF in (21)), to be true in the scenario in (30), as shown in (31).

(29) $\left[{ }^{*} * \operatorname{tall}\right](\mathrm{D})(\mathrm{X})=$ True iff for all $\mathrm{d} \in \mathrm{D}$ there is a $\mathrm{x} \in \mathrm{X}$ such that $\llbracket$ tall $](\mathrm{d})(\mathrm{x})=$ True and for all $\mathrm{x} \in \mathrm{X}$ there is a $\mathrm{d} \in \mathrm{D}$ such that $\llbracket$ tall $](\mathrm{d})(\mathrm{x})=$ True.

(30) $\mathrm{C}=\{\{$ Bill, John $\},\{$ Fred, Ted $\}\}$

Bill is 6', John is 5', Fred is 5'10', Ted is 5'4'.

(31) There is a plurality of degrees D (namely, $\left\{6^{\prime}, 5^{\prime}\right\}$ ) such that $\left[\mathbb{H}^{* *}\right.$ tall $\left.*_{\text {student }}\right](\mathrm{D})(\{\mathrm{John}, \mathrm{Bill}\}) \quad$ True $) \quad$ and ${ }^{* *}$ tall $\left.*_{\text {student }}\right](\mathrm{D})(\{$ Fred, Ted $\})=$ False

In other words, the presupposition in (25b) guarantees that the shortest member of the subject term is taller than everyone who is not a member of the subject term. Figures 1 and 2 on the next page further illustrate how (25b) yields the correct interpretation for (21).

This proposal still doesn't account for Observation 2' (in fact, it predicts Stateva's Observation 2, which we take to be wrong, to hold). We therefore offer (32) as the semantics for - est ( $\mathrm{C}$ is a pair consisting of a comparison set $-(\operatorname{Comp}(\mathrm{C}))$ and a cut-off (which can be either a singularity or a plurality of degrees) - Cut-off(C)).

(32) $\quad[-e s t]^{C}(\mathrm{R})(\mathrm{X})$ is defined only if (i) $\mathrm{X} \in \operatorname{Comp}(\mathrm{C})$, (ii) for all $Y \in \operatorname{Comp}(C)$ such that $Y \neq X: Y$ doesn't overlap $X$, and (iii) for all $\mathrm{Y} \in \mathrm{Comp}(\mathrm{C})$ : there is a (singularity or plurality of degrees) $\mathrm{D}$ such that $\mathrm{R}(\mathrm{D})(\mathrm{Y})=$ True.

Whenever defined, [-est $]^{C}(\mathrm{R})(\mathrm{X})=$ True iff $\mathrm{R}(\mathrm{Cut}-\mathrm{off}(\mathrm{C}))(\mathrm{X})=$ True and for all $\mathrm{Y}$ such that $\mathrm{Y} \in \operatorname{Comp}(\mathrm{C})$ and $\mathrm{Y} \neq \mathrm{X}, \mathrm{R}(\mathrm{Cut}-\mathrm{off}(\mathrm{C}))(\mathrm{Y})=$ False.

(33) Whenever defined, $\llbracket$ John be [-est [tall student $]] \mathbb{C}^{\mathrm{C}}=$ True iff John's tallness is at least the cut-off of $\mathrm{C}$ and for every $\mathrm{y} \in \mathrm{C}, \mathrm{y} \neq \mathrm{John}$ : $\mathrm{y}$ 's tallness is less than this cut-off.

(34) Whenever defined, $\llbracket$ John and Bill be [-est $[* *$ tall $*$ student $]]]^{C}=$ True iff John's tallness is at least the cut-off of C and Bill's tallness is at least the cut-off of $\mathrm{C}$, but everyone else's tallness is less than the cutoff of $\mathrm{C}$.

The only interpretation of (33) - with a singular superlative expression which would make its utterance felicitous is one where the cut-off is determined in a way that allows only one singular individual to have it. If the context doesn't supply such a cut-off, the initial cut-off has to be readjusted to enable a felicitous utterance of the sentence.

A variation on this very same solution would be one where the cut-off is an argument of -est, and is represented by a degree-denoting pronominal 
expression in the syntactic tree, as follows (with the necessary adjustments in the semantics of -est).

\section{[John and Bill [[-est pro $]$ [**tall *student $]]]$}

And yet another variation would be one where pro $_{\mathrm{j}}$ denotes a number. This would be consistent with the fact that plural superlatives that include numbers (e.g., the tallest five students; see Scontras 2008 for discussion of these cases) force an interpretation where five students indeed meet the contextual cut-off (in the same way singular morphology, with or without an overt numerical expression, as in the (one/single) tallest student, forces an interpretation where only one student is above the cut-off.

In the next section we consider some advantages and disadvantages of alternative solutions to the distributivity problem.

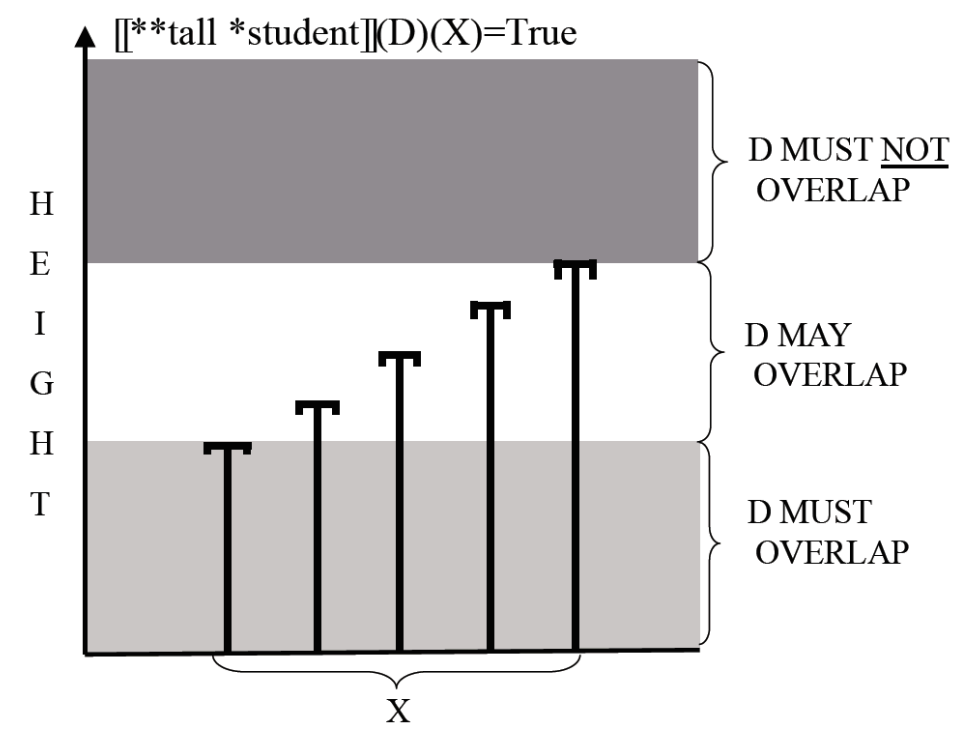

Figure 1: Relation between $\mathrm{X}$ and $\mathrm{D}$ under presupposition of $* *$ (TRUE)

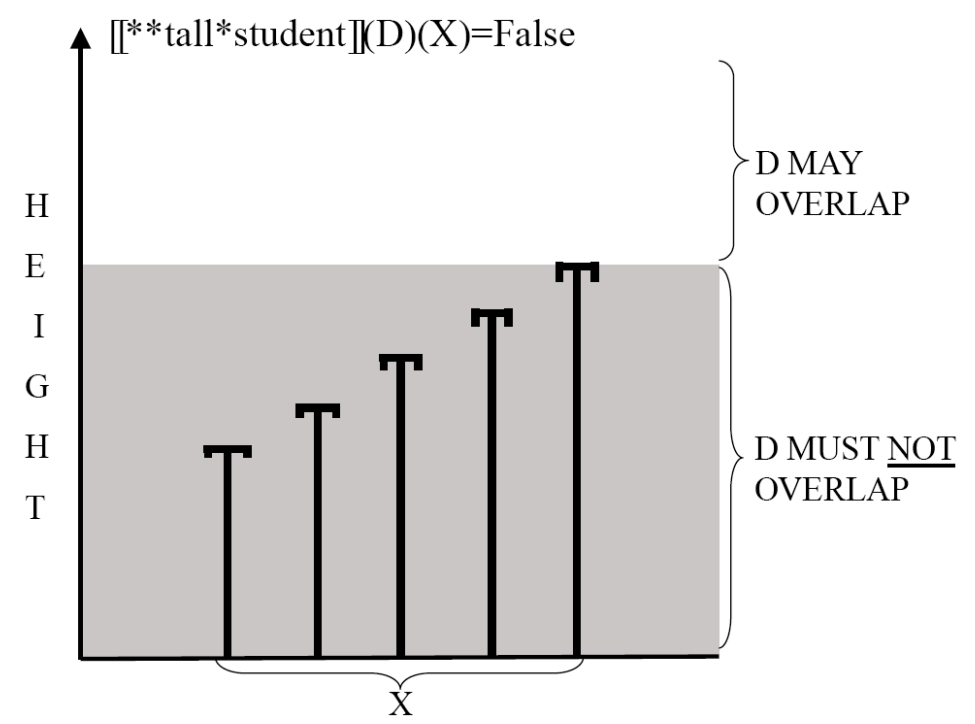

Figure 2: Relation between D and X under presupposition of ** (FALSE) 


\section{Alternative Solutions to the Distributivity Problem}

In this section we consider some alternatives to the semantics in (26), repeated below as (36), and to the LF in (21) (repeated below as (37)).

(36) $\quad[-e s t] \mathbb{f}^{\mathrm{C}}(\mathrm{R})(\mathrm{X})$ is defined only if (i) $\mathrm{X} \in \mathrm{C}$, (ii) for all $\mathrm{Y} \in \mathrm{C}$ such that $\mathrm{Y} \neq \mathrm{X}$ : $\mathrm{Y}$ doesn't overlap $\mathrm{X}$, and (iii) for all $\mathrm{Y} \in \mathrm{C}$ : there is a (singularity or plurality of degrees) $D$ such that $R(D)(Y)=$ True.

Whenever defined, $[-e s t]^{C}(\mathrm{R})(\mathrm{X})=$ True iff there is a $\mathrm{D}$ such that $R(D)(X)=$ True and for all $Y \neq X$ such that $Y \in C: R(D)(Y)=$ False.

[John and Bill [-est [**tall *student]]]

Since, as we saw in section 1.2, the distributivity problem can be solved independently of the cut-off problem, we largely ignore the cut-off problem for simplicity.

\subsection{Singular Degrees; Plural Individuals}

One possible alternative solution to the problem posed by (12) (repeated below as (38)) was already mentioned in Section 1 (see (13)), and is repeated below as (39).

\section{[John and Bill *[-est [tall student]]] \\ [John and Bill [-est [tall $\left.*_{\text {student }]]}\right]$}

As we noted in section 1, by adjusting the semantics of tall and combining tall with *student, we derive the function $\left[\lambda \mathrm{d} \in \mathrm{D}_{\mathrm{d}} \cdot \lambda \mathrm{x} \in \mathrm{D}_{\mathrm{e}} \cdot \mathrm{x}\right.$ is a singularity or a plurality of students and $x$ is at least $d$ tall]. But we have to be more precise about what it means for a plurality to be tall to some (singular) degree $\mathrm{d}$. Perhaps we can stipulate that it means that every singular member of the plurality is at least d-tall (while adding a presupposition similar to the one in (22d)).

(40) $\llbracket$ tall $](\mathrm{d})(\mathrm{X})$ is defined only if:

If there is a $x \in X$ such that $x$ 's tallness is at least $d$, then for every $x \in X$, $\mathrm{x}$ 's tallness is at least $\mathrm{d}$.

Whenever defined, $\llbracket$ tall $\rrbracket(\mathrm{d})(\mathrm{X})=$ True iff for every $\mathrm{x} \in \mathrm{X}$ : $\mathrm{x}$ 's tallness is at least $\mathrm{d}$.

Coupled with the semantics for - est in (41), this would yield the semantics in (42) for John is the tallest student and that in (43) for (1).

(41) $\llbracket$-est $\rrbracket^{C}(\mathrm{R})(\mathrm{X})$ is defined only if: (i) $\mathrm{X} \in \mathrm{C}$, (ii) for all $\mathrm{Y} \in \mathrm{C}$ such that $Y \neq X$ : $Y$ doesn't overlap $X$, and (iii) for all $Y \in C$ : there is a degree $d$ such that $\mathrm{R}(\mathrm{d})(\mathrm{Y})=$ True.

Whenever defined, $[-e s t] \mathbb{C}^{\mathrm{C}}(\mathrm{R})(\mathrm{X})=$ True iff there is a $\mathrm{d}$ such that $\mathrm{R}(\mathrm{d})(\mathrm{X})=$ True and for all $\mathrm{Y}$ such that $\mathrm{Y} \in \mathrm{C}$ and $\mathrm{Y} \neq \mathrm{X}$ : $\mathrm{R}(\mathrm{d})(\mathrm{Y})=$ False. 
(42) Whenever defined, [John [-est [tall student $]] \rrbracket=$ True iff John is taller than everyone else.

(43) Whenever defined, [John and Bill [-est [tall *student $]] \rrbracket=$ True iff the shortest among $\{$ John, Bill $\}$ is taller than everyone else.

This analysis mimics the predictions of our proposal in (25)-(26) regarding (1). However, unlike the presupposition in (25), which was shown to be motivated independently as a general presupposition of '**'-predicates (see discussion of (22d)), the presupposition in (40) is not independently motivated. So although both proposals make the exact same predictions regarding (1), the proposal in (25)-(26) seems to us more explanatory, as it contains fewer stipulations.

It is worth noting that that an analysis in the spirit of (40)-(41) may work well for 'group' plural superlatives (mentioned briefly in section 1.1). Still, the existence of group readings doesn't obviate the need for a semantics of non-group - that is to say, absolute - readings of plural superlatives (and the proposal in (36)-(37) works just as well for group readings, once we have a procedure for mapping each group to the degree that "represents" it).

The remaining alternatives discussed below presuppose that tall is interpreted as in (8a) (repeated below as (44)).

(44) For any singular degree $d$ and any singularity $x$, $\llbracket$ tall $\rrbracket(d)(x)=$ True iff $\mathrm{x}$ 's tallness is at least $\mathrm{d}$.

\subsection{Plural Morphology in the Noun Phrase is not Interpreted}

Another possible alternative says that plural morphology in the noun phrase is not semantically interpreted; it is rather the result of a syntactic agreement mechanism between the subject and the predicate. According to this solution, the superlative morpheme has the meaning in (45), where distributivity is built-in.

(45) $\llbracket-e s t]^{C}(R)(X)$ is defined only if for every $Y \in C$ distinct from $X, Y$ doesn't overlap $\mathrm{X}$. Whenever defined, $[-e s t]]^{\mathrm{C}}(\mathrm{R})(\mathrm{X})=$ True iff there is a degree $d$ such that for every $x \in X: R(d)(x)=$ True, and for every $Y$ in $C$ distinct from $X$ and for every $y \in Y: R(d)(y)=$ False.

This will yield (46) and (47) as the LFs and interpretations of John is the tallest student and John and Bill are the tallest students.

(46) Whenever defined, [ John [-est [tall student $]] \rrbracket=$ True iff John is taller than everyone else.

(47) Whenever defined, [[ John and Bill [-est [tall student]] ]= True iff the shortest singular individual among $\{$ John, Bill $\}$ is taller than everyone else. 
The problem with this solution is that plural morphology on nouns (and adjectives) does have a semantic effect, as shown by the following identity sentence. At least one of the definite descriptions has to contain semantic plurality (and if one of them does, there is no reason why the other shouldn't).

(48) The tallest students are the smartest students.

While there are various possible mechanisms for interpreting plural morphology in noun/determiner phrases (see, for example, Sauerland 2004, Ionin and Matushansky 2006), it is clear that (48) requires some mechanism that doesn't completely ignore plural morphology in the noun phrase.

\subsection{Degree-operator Movement (Stateva 2005)}

This solution was considered (and rejected) by Stateva. It offers (49) - where the superlative morpheme has scoped over ' $*$ ' - as an alternative to the LF in (12). This requires adjusting the semantics of -est as in, for example, (50).

[John and Bill [-est $\lambda_{1} *\left[t_{1}\right.$-tall student $\left.\left.]\right]\right]$

(50) $\llbracket$-est $\rrbracket^{C}(R)(X)$ is defined only if: (i) $\mathrm{X} \in \mathrm{C}$, (ii) for all $\mathrm{y} \in \mathrm{C}$ such that $\mathrm{y} \neq \mathrm{X}$ : $\mathrm{y}$ is a singularity that doesn't overlap $X$, and (iii) for all $Y \in C$ : there is a degree $d$ such that $R(d)(Y)=$ True.

Whenever defined, $\llbracket-$ est $\rrbracket \mathbb{C}^{\mathrm{C}}(\mathrm{R})(\mathrm{X})=$ True iff there is a $\mathrm{d}$ such that $\mathrm{R}(\mathrm{d})(\mathrm{X})=$ True and for all $\mathrm{y}$ such that $\mathrm{y} \in \mathrm{C}$ and $\mathrm{y} \neq \mathrm{x}: \mathrm{R}(\mathrm{d})(\mathrm{Y})=$ False.

(51) Whenever defined, $[$ John [-est [tall student $]]]^{C}=$ True iff John is taller than everyone else in $\mathrm{C}$.

(52) Whenever defined, $\left[\text { John and Bill }\left[\text {-est } \lambda_{1} *\left[t_{1} \text {-tall student }\right]\right]\right]^{C}=$ True iff there is a degree $\mathrm{d}$ such that $\left[\lambda_{1} *\left[t_{1}\right.\right.$-tall student $\left.]\right] \mathbb{C}^{\mathrm{C}}(\{\mathrm{John}, \mathrm{Bill}\})=$ True, and for all $\mathrm{y} \in \mathrm{C}$ such that $\mathrm{y} \neq \mathrm{X}, \llbracket \lambda_{1} *\left[t_{1}\right.$-tall student $] \mathbb{C}^{\mathrm{C}}(\mathrm{y})=$ False.

The solution delivers the right truth conditions for John and Bill are the tallest students: it requires that the shorter of John and Bill (or if they are both of equal height, that both John and Bill) be taller than any other relevant singular individual.

The problem with this solution, as Stateva notes, is that usually, degree operators cannot scope over quantifiers (a generalization referred to as Kennedy's Generalization in Heim 2000; see Kennedy 1999). This is shown (see Heim 2000) by the fact that Every student is less than 5 feet tall is unambiguous.

(53) a. [every student $]\left[\lambda_{1}[\right.$ less than $5 \mathrm{ft}]\left[\lambda_{2}\left[t_{1}\right.\right.$ is $t_{2}$-tall $\left.\left.]\right]\right]$ For every student $\mathrm{x}$, $\mathrm{x}$ 's tallness is less than 5 feet. 
b. [less than $5 \mathrm{ft}]\left[\lambda_{1}\right.$ [every student $]\left[\lambda_{2}\left[t_{2}\right.\right.$ is $t_{1}$-tall $\left.\left.]\right]\right]$ The maximal $\mathrm{d}$ such that for every student $\mathrm{x}, \mathrm{x}$ is d-tall - is less than 5 feet.

(not attested)

(54) For every $\mathrm{P}$ of type $<\mathrm{d}, \mathrm{t}>$, [less than $5 \mathrm{ft} \rrbracket(\mathrm{P})=$ True iff $\operatorname{Max}(\mathrm{P})<5 \mathrm{ft}$.

Not all quantifiers are subject to Kennedy's Generalization (see Heim 2000), as shown by (55), which, on its split-scope reading, presumably has the LF in (56), which involves less-movement (but see Sharvit and Stateva 2002 for a way to derive the truth conditions without less-movement).

(55) John needs to climb a less high mountain than Bill (needs to climb).

Possible reading: John's mountain-climbing achievement needs are less demanding than Bill's mountain-climbing achievement needs.

(56) $\left[\right.$ less $\left[\lambda_{1}\left[\right.\right.$ Bill needs to climb a $t_{1}$-high mountain $\left.\left.]\right]\right]\left[\lambda_{2}[\right.$ John needs to climb a $t_{2}$-high mountain]]

$$
\llbracket \text { less } \rrbracket(\mathrm{P})\left(\mathrm{P}^{\prime}\right)=\text { True iff } \operatorname{Max}\left(\mathrm{P}^{\prime}\right)<\operatorname{Max}(\mathrm{P})
$$

Stateva's point is that '*' IS a quantifier that must respect Kennedy's Generalization, as evidenced by the lack of ambiguity of (58).

(58) Scott and Bill are less than 5 feet tall.

a. For every $\mathrm{x}, \mathrm{x} \in\{\mathrm{Scott}, \mathrm{Bill}\}, \mathrm{x}$ 's tallness is less than 5 feet.

(attested)

b. The maximal $d$ such that for every $\mathrm{x}, \mathrm{x} \in\{\mathrm{Scott}, \mathrm{Bill}\}$, $\mathrm{x}$ is $\mathrm{d}$-tall - is less than 5 feet.

(not attested)

Therefore, this solution cannot be adopted either.

\section{4. "Shrinking” C (Stateva 2005)}

The last alternative solution we consider is also due to Stateva (and it is the solution she ultimately adopts). The idea here is to remove from (9) (repeated below as (59)) the presupposition that the external argument of -est is a member of $\mathrm{C}$ ( see (60)).

(59) $[- \text {-est }]^{C}(\mathrm{R})(\mathrm{x})$ is defined only if (i) $\mathrm{x} \in \mathrm{C}$, and (ii) for all $\mathrm{y} \in \mathrm{C}$ : there is a $\mathrm{d}$ such that $\mathrm{R}(\mathrm{d})(\mathrm{y})=$ True.

Whenever defined, $[- \text { est }]^{C}(\mathrm{R})(\mathrm{x})=$ True iff there is a d such that $\mathrm{R}(\mathrm{d})(\mathrm{x})$ $=$ True and for all $\mathrm{y} \neq \mathrm{x}$ such that $\mathrm{y} \in \mathrm{C}: \mathrm{R}(\mathrm{d})(\mathrm{y})=$ False.

(60) $[- \text {-est }]^{C}(\mathrm{R})(\mathrm{x})$ is defined only if for all $\mathrm{y} \in \mathrm{C}$ : there is a degree $\mathrm{d}$ such that $R(d)(y)=$ True. 
Whenever defined, [-est $\rrbracket^{C}(\mathrm{R})(\mathrm{x})=$ True iff there is a d such that $\mathrm{R}(\mathrm{d})(\mathrm{x})$ $=$ True and for all $y \neq x$ such that $y \in C: R(d)(y)=$ False .

The semantics in (60) allows us to obtain from the LF in (12) (John and Bill *[-est [tall student]]), where '*' has scope over - est, the interpretation "John is taller than any $\mathrm{y} \in \mathrm{C}$ and Bill is taller than any $\mathrm{y} \in \mathrm{C}$, where $\mathrm{C}$ excludes both John and Bill", in accordance with Observation 1.

The problem with this solution is that ' $\mathrm{x} \in \mathrm{C}$ ' is indeed a presupposition of -est. It is hard to show this using standard presupposition tests. As an illustration, consider von Fintel's (2004) Wait-a-Minute test which, when applied to even, shows that even $P(x)$ presupposes that $P$ holds of someone and asserts that $P$ holds of $x$. While (61b), which questions the truth of what Even John failed the exam presupposes, is well-formed, (61c), which questions the truth of what the sentence asserts, is odd.

a. Even John failed the exam.

b. Wait a minute! I didn't know someone failed the exam.

c. \#Wait a minute! I didn't know that John failed the exam.

The test, however, is useless when it comes to determining the status of ' $\mathrm{x} \in \mathrm{C}$ ' with respect to -est. While (62b) is good, both (62c) and (62d) are odd, which means that the test singles out some of the presuppositions of (62a) (specifically, that every member of $\mathrm{C}$ is a student with some degree of tallness), but not all of them (specifically, 'John $\in \mathrm{C}$ ').
a. John is the tallest student.
b. Wait a minute! I didn't know John was a student.
c. \#Wait a minute! I didn't know John was relevant/salient.
d. \#Wait a minute! I didn't know John was the tallest student.

The fact that standard presupposition tests are not applicable to inferences of this sort is not a problem for the theory of presuppositions (nor is it a problem for the claim that ' $\mathrm{x} \in \mathrm{C}$ ' is a presupposition of -est); it just means that we need other ways to determine the status of ' $\mathrm{x} \in \mathrm{C}$ ' with respect to -est.

Luckily, we do have a way to determine that ' $\mathrm{x} \in \mathrm{C}$ ' is, at the very least, true whenever ' $\mathrm{x}$ is R-est' is true. Consider the intuitively contradictory (63a) interpreted relative to a $\mathrm{C}$ that excludes John and Bill (an option allowed by Stateva's solution). The interpretation in (63b) is non-contradictory.

a. \#\#John is the tallest student and Bill is too.

b. Whenever defined (e.g., $\mathrm{C}=\{$ Mary, Fred, Sally $\}$ ), [John [-est [tall student]] and Bill [-est [tall student]] $\mathbb{C}^{\mathbb{C}}=$ True iff John is taller than anyone in $\mathrm{C}$ and Bill is taller than anyone in $\mathrm{C}$.

To solve this problem, we may stipulate a pragmatic constraint (or procedure) according to which every minimal clause is interpreted relative to the largest $\mathrm{C}$ possible. What this means is that we first interpret John [-est [tall student]] relative to the largest $\mathrm{C}$ possible (which includes everyone), and then we interpret Bill [-est [tall student]] relative to the largest $\mathrm{C}$ possible (which, again, includes everyone), and we get a contraction, as desired. 
However, if the pragmatic requirement to interpret minimal clauses relative to the largest $\mathrm{C}$ possible always holds, the tallest students in an argument position should also be interpreted relative to the largest $\mathrm{C}$ possible. This means that in every context where John and Bill are taller than everyone else, the tallest students obligatorily refers to John and Bill, as shown in (64) (assume that the presupposes existence of a unique maximal individual satisfying the relevant predicate).

[I the tallest students left $]^{\mathrm{C}}$ is defined iff $\llbracket$ left $\left.]\right]^{\mathrm{C}}\left([\text { the }]^{\mathrm{C}}\left(\left[{ }^{*}\right.\right.\right.$ [-est [tall student $]] \mathbb{I}^{\mathrm{C}}$ )) is defined; i.e., only if there a plurality of individuals $\mathrm{X}$ such that: $\left[{ }^{*}[\right.$-est $[$ tall student $]] \mathbb{I}^{\mathrm{C}}(\mathrm{X})=$ True, and for every plurality $\mathrm{Y}$ such that $\left[{ }^{*}[\right.$-est $[$ tall student $]] \mathbb{I}^{\mathrm{C}}(\mathrm{Y})=$ True, $\mathrm{Y} \subseteq \mathrm{X}$.

If $\mathrm{C}=\{$ Fred, Mary, Sally $\}$, [[ the tallest students $] \mathbb{I}^{\mathrm{C}}=\{\mathrm{John}, \mathrm{Bill}\}$. If $\mathrm{C}=\{$ Mary, Sally $\}, \mathbb{[}[$ the tallest students $] \mathbb{I}^{\mathrm{C}}=\{$ John, Bill, Mary $\}$.

The point is that in some contexts we may want the tallest students to refer to one or more shorter individuals. But according to the proposed procedure, we must choose the largest $\mathrm{C}$ that doesn't lead to a contradiction.

Proponents of this view may want to suggest that we change the requirement to interpret the superlative relative to the largest $\mathrm{C}$ possible, to the more specific "largest C permitted by the contextually supplied cut-off point." But if we are admitting reference to a cut-off in the semantics of -est, we no longer need to exclude the subject term from $\mathrm{C}$ (suggesting, somewhat implausibly, that the members of the subject term are not contextually salient; on this, see Fitzgibbons 2007).

We may attempt yet another way to predict the contradictory reading of (63a): let us say that sentences with superlatives are evaluated relative to a set $\mathrm{C}$ of contextually-salient individuals and a function $\mathrm{F}$ from individuals to sets such that for every $\mathrm{x}, \mathrm{F}(\mathrm{x})$ includes every member of $\mathrm{C}$ but $\mathrm{x}$ (thus avoiding the strange implication that $\mathrm{x}$ is not salient).

a. Whenever defined, $[- \text { est }]^{\mathrm{F}, \mathrm{C}}(\mathrm{R})(\mathrm{x})=$ True iff $\mathrm{x}$ is R-er than every singular individual which is a part of some individual in $\mathrm{F}(\mathrm{x})$.

b. Whenever defined, [John is the -est [tall student $]$ and Bill is too $\rrbracket^{\mathrm{F}, \mathrm{C}}$ $=$ True is iff John is taller than any $\mathrm{x} \in \mathrm{F}(\mathrm{John})$ and Bill is taller than any $\mathrm{x} \in \mathrm{F}(\mathrm{Bill})$.

But applying this semantics to [John and Bill *[-est [tall student]]] brings back the familiar contradiction from Observation 1. We therefore maintain that the semantics of -est is as in (59), which without any further stipulations correctly predicts (1) to be non-contradictory, and (63a) to be contradictory.

\section{Conclusion}

We proposed a unified semantics for singular and (absolute) plural superlatives, which relies on: (a) an independently motivated pluralization operation of $<\mathrm{d},<\mathrm{e}, \mathrm{t}>>$-predicates; and (b) a contextually supplied cut-off degree. The former solves the distributivity problem and the latter solves the 
cut-off problem. We rejected some alternative solutions, including a solution involving two distinct superlative morphemes.

\section{References}

Beck, Sigrid: 2001, 'Reciprocals are Definites', Natural Language Semantics 9, 69-138.

von Fintel, Kai: 2004, 'Would you Believe It? The King of France is Back! Presuppositions and Truth-value Intuitions, in $\mathrm{M}$. Reimer and $\mathrm{A}$. Bezuidenhout (eds.) Descriptions and Beyond, Oxford University Press.

Fitzgibbons, Natalia: 2007, 'The Interpretation of Plural Superlatives', Ms. University of Connecticut.

Heim, Irene: 1999, 'Notes on Superlatives', Ms. MIT.

Heim, Irene: 2000, 'Degree Operators and Scope'. Proceedings of SALT X. CLC Publications.

Herdan, Simona: 2007, 'A Superlative Theory of Amount Relatives' in C. Chang and H. Haynie (eds.) Proceedings of WCCFL 26, Cascadilla Press.

Ionin, Tania and Ora Matushansky: 2006, 'The Composition of Complex Cardinals', Journal of Semantics 23, 315-360.

Kennedy, Christopher: 1999, Projecting the Adjective: the Syntax and Semantics of Gradability and Comparison, Garland, New York.

Landman, Fred: 1989, 'Groups, I', Linguistics and Philosophy 12, 559-605.

Link, Gödehard: 1983, 'The Logical Analysis of Plurals and Mass Terms: A Lattice Theoretical Approach', in R. Bäuerle, C. Schwarze, and A. von Stechow (eds.) Meaning, Use, and the Interpretation of Language, de Gruyter, Berlin.

Löbner, Sebastian: 1987, 'The Conceptual Nature of Natural Language Quantification', in I. Ruzsa and A. Szabolics (eds) Proceedings of the 1987 Debrecen Symposium of Logic and Language, Akademiai Kiado, Budapest.

Matushansky, Ora and E.G. Ruys: 2006, 'Meilleurs Voux: Quleques Notes sur la Comparaison Plurielle', in O. Bonami and P. Cabredo Hofherr (eds.) Empirical Issues in Syntax and Semantics 6, 309-330.

Quine, W.V.O.: 1969, Set Theory and Its Logic, Harvard University Press.

Sauerland, Uli: 2004, 'A Comprehensive Semantics for Agreement', Paper presented at the Phi-Workshop, McGill University, Montreal, Canada.

Schwarzschild, Roger: 1994, 'Plurals, Presuppositions and the Sources of Distributivity', Natural Language Semantics 2, 201-248.

Schwarzschild, Roger: 1996, Pluralities, Kluwer Academic Publishers.

Scontras, Gregory: 2008, The Semantics of Plural Superlatives, MA Thesis, Boston University.

Sharvit, Yael and Penka Stateva: 2002, 'Superlative Expressions, Context, and Focus', Linguistics and Philosophy 25, 453-505.

Stateva, Penka: 2005, 'Presuppositions in Superlatives', Ms. ZAS Berlin.

Sternefeld, Wolfgang: 1998, 'Reciprocity and Cumulative Predication', Natural Language Semantics 6, 303-337. 